\title{
Lipid Metabolism, Disorders and Therapeutic Drugs - Review
}

\author{
Vijayakumar Natesan ${ }^{1}$ and Sung-Jin Kim ${ }^{2, *}$ \\ ${ }^{1}$ Department of Biochemistry and Biotechnology, Faculty of Science, Annamalai University, Annamalainagar 608002, Tamilnadu, \\ India \\ ${ }^{2}$ Department of Pharmacology and Toxicology, Metabolic Diseases Research Laboratory, School of Dentistry, Kyung Hee University, \\ Seoul 02447, Republic of Korea
}

\begin{abstract}
Different lifestyles have an impact on useful metabolic functions, causing disorders. Different lipids are involved in the metabolic functions that play various vital roles in the body, such as structural components, storage of energy, in signaling, as biomarkers, in energy metabolism, and as hormones. Inter-related disorders are caused when these functions are affected, like diabetes, cancer, infections, and inflammatory and neurodegenerative conditions in humans. During the Covid-19 period, there has been a lot of focus on the effects of metabolic disorders all over the world. Hence, this review collectively reports on research concerning metabolic disorders, mainly cardiovascular and diabetes mellitus. In addition, drug research in lipid metabolism disorders have also been considered. This review explores lipids, metabolism, lipid metabolism disorders, and drugs used for these disorders.
\end{abstract}

Key Words: Lipid metabolism, Disorders, Diabetes, Cardiovascular disorder, Drugs

\section{INTRODUCTION}

Lipids are organic compounds that are insoluble in water and soluble in organic solvents. They are esters of fatty acids, rarely containing alcohol or phosphate functional group molecules, and comprise triglycerides, phospholipids, and steroids. They are the energy reserves of animals and perform various functions, such as maintenance of body temperature, whilst being the key constituents of cell membranes and serving as chemical messengers (Tocher, 2003; Ratnayake and Galli, 2009). The human body requires various types of useful lipid fat to maintain the healthy functions of its parts (Ahmed et al., 2020). Balancing lipid levels in the blood is an important part of staying healthy. Abnormal levels of blood lipids cause fat deposits in artery walls, which initiates complications inside the blood vessels. Causes for high lipid levels include diabetes, alcoholism, kidney disease, hypothyroidism, liver disease, and stress. Augmented lipids easily adhere to the blood's circulating nerve walls, and the growing fatty scale causes a variety of atherosclerosis disorders, such as stroke or heart attack (Nelson, 2013).

A lack of chemical reactions in our bodies causes metabolic diseases and lowers our quality of life. The enzymes needed to metabolize lipids may not work properly or are not produced enough (Lattimer and Haub, 2010). Excessive lipids are stored, causes permanent cellular and tissue damage, predominantly in the brain and peripheral nervous system, resulting in metabolic disorders such as Gaucher's disease, TaySachs disease, Niemann-Pick disease (NPD), etc. (Solomon and Muro, 2017). Obesity is now a common metabolic disorder, involving an excessive amount of body fat. It increases the risk of other diseases and health problems, such as heart disease, diabetes, high blood pressure, and certain cancers. Altered intestinal microbiota may stimulate hepatic fat deposition, also causing obesity and other metabolic disorders (Arslan, 2014; Song et al., 2019). Almost half of all cardiovascular disease-related fatalities occur as a result of a metabolic imbalance (Knopp, 1999). Obesity is a major cause of cardio metabolic risk factors such as elevated plasma glucose levels, atherogenic dyslipidemia, elevated blood pressure, and so on (Grundy, 2009).

According to the Mayo Clinic, while certain metabolic abnormalities can be discovered by continuous screening tests at birth, the majority are diagnosed after the onset of symptoms in adulthood. For example, the population of gut microbiota microorganisms in the human digestive system that are involved in beneficial metabolic action is high. (Dibaise et al., 2008). However, obese metabolic disease is caused by

\section{Open Access https://doi.org/10.4062/biomolther.2021.122}

This is an Open Access article distributed under the terms of the Creative Commons Attribution Non-Commercial License (http://creativecommons.org/licenses/by-nc/4.0/) which permits unrestricted non-commercial use, distribution, and reproduction in any medium, provided the original work is properly cited.
Received Jul 19, 2021 Revised Sep 24, 2021 Accepted Oct 1, 2021

Published Online November 1, 2021

\section{${ }^{*}$ Corresponding Author}

E-mail:kimsj@khu.ac.kr Tel: +82-2-961-0868 
pathophysiological interactions that result in aberrant negative metabolic activity (Hur and Lee, 2015). Based on the child's viewpoint and progress, this condition can be detected as early as childhood. Because of deficiencies in the diagnostic and screening processes (Denisenko et al., 2020), physicians and drug researchers have yet to identify the optimal therapy for metabolic diseases (Metbd). Metbd caused by chemical reactions begins with obesity and progresses via different illnesses, such as infertility, hypothyroidism, hypoactive sexual desire disorder, nonalcoholic steatohepatitis, testosterone replacement, vaginal atrophy, cancer, type I diabetes, and type II diabetes (Pischon et al., 2008). In recent years, lipid metabolism disease insulin resistance has become a frequent worldwide concern, which necessitates more medication research and diagnosis (Lark et al., 2012; Monnerie et al., 2020). Obesityrelated illnesses are being caused by the excessive intake of saturated fat lipids (Cena and Calder, 2020). The absence of certain lipids, such as polyunsaturated lipids and phospholipids, causes inflammation and disrupts the glucose-insulin balance (Novgorodtseva et al., 2011; Glass and Olefsky, 2012). Furthermore, several studies have indicated that the contribution of lipoxin A4 lipid levels has an influence on periodontal disease, kwonlic syndrome, and other chronic issues (Doğan et al., 2019). According to the National Institute of Neurological Disorders and Stroke, the impact of excessive fat accumulation (lipids) is the source of many health concerns, such as tissue damage, and liver, brain, bone marrow, peripheral nervous system, and spleen disorders. The data in this investigation reveals a variety of problems caused by alterations in lipid metabolism. As a result, this study summarizes the different Metbd and current medication development reports.

\section{LIPID TYPES AND STRUCTURES}

Aqueous insoluble lipids are molecules with complex structures as a result of several biochemical transformations (Fahy et al., 2011). Because of the participation of different enzymes and biological substances, the process of lipidomics is important to comprehend (Nilsson et al., 2019). Lipids contain hydrocarbons, a diverse and ubiquitous group of compounds that are non-polar soluble in organic solvents. They have significant structural variety, based on their variable chain length, and have a mass of oxidative, reductive, substitutional, and ring-forming capability, also with sugar residues and other functional groups (Fahy et al., 2011). Based on this, lipids are divided into several types, including saturated and unsaturated fatty acids, waxes, glycerol phospholipids, sphingo lipids, and glycosphingo lipids (Fahy et al., 2005). Lipids are liquids or non-crystalline solids with colorless, tasteless, and odorless qualities, and are energy-rich organic compounds with no ionic charge. The acetyl, propenyl, and isoprene functional groups of the building components of lipids also serve as hormones. Polyunsaturated fatty acids carry out a signaling function and are responsible for membrane structure (Cani et al., 2008; Bazinet and Layé , 2014).

\section{LIPID OR FATTY ACID SYNTHESIS}

Lipids or fatty acids are important components of the human body and have multiple functions in both health and dis- eases. Different lipids are synthesized by our body, based on the functional area, and are produced by lipogenic tissues in the presence of cytosol (Tracey et al., 2018). Lipids or fatty acids are synthesized from acetyl-CoA and NADPH through the action of enzymes called fatty acid synthases. Seven replications of four-cycle reactions were observed by Tracey et al. (2018) with various fatty synthesis mechanisms (Nelson, 2013). Except for some essential fatty acids, the human body is able to synthesize most of the required fatty acids directly from precursors (Nagy and Tiuca, 2017). Acetyl-CoA carboxylase beta $(A C C 2)$ is involved in the carboxylation of acetylCoA to malonyl-CoA. Malonyl-CoA is the substrate for fatty acid synthase complex and is also a key molecule regulator of both the biosynthesis and oxidation of fatty acids (Leśniak et al., 2015; Alves-Bezerra and Cohen, 2017). The Coronavirus host protein has ACC2 and a chief lipid complex, which are arranged on the mitochondrial membrane (Castle et al., 2009). Long chain fatty acid synthesis is found in all cells and organisms, serving as the universal building block of sphingolipids, glycerophospholipids, triacylglycerols, and wax-esters (Uttaro, 2006). Similarly, three fatty acid biosynthetic pathways were observed in different parts of Toxoplasma (Coppens et al., 2014). From the results, this review observed the importance of lipid synthesis in various organisms and pathways.

\section{LIPID FUNCTIONS AND ITS METABOLISM}

Lipid metabolism is involved in different active functions of our body, such as energy storage, hormone regulation, nerve impulse transmission, and fat-soluble nutrient transportation. Lipids serves as an energy source with high caloric density, providing $9 \mathrm{kcal}$ of energy when compared to protein and carbohydrates, which can also store 100,000 kcal of energy in our body functions without any intake of food for 30-40 days, only requiring sufficient water (Ophardt, 2003). Biochemical lipids are stowed in cells all over the body, in specific varieties of connective tissue, named adipose. Lipids protect human organs, such as the spleen, liver, heart, and kidneys, from damage (Church et al., 2012).

Lipids that exist in the blood are absorbed through liver cells and provide the correct concentrations to various parts of the body. The liver plays a key and vital role in lipid metabolism (Ophardt, 2003). The liver serves as a substitute reservoir for storing extensive quantities of excess fat. Through prolonged energy overload, the unspent excess energy is stored in adipose tissue and in hepatocytes in the form of triglycerides (Huang et al., 2011). The metabolism cycle is extended to the citric acid cycle, the urea cycle, and the citric cycle (Arumugam and Natesan, 2017).

Fatty acids are degraded via oxidation, which releases large amounts of ATP and produces sensitive oxygen (Rosca et al., 2012). The glycerolipids biosynthesized through snglycerol3-phosphate dominate in the liver and adipose tissue (Athenstaedt and Daum, 2006). This review observed various useful metabolic functions of proteins enabling an understanding of metabolic disorders (Huang and Freter, 2015; Trebatická et al., 2017; Musso et al., 2018; Yan and Horng, 2020). 


\section{LIPID METABOLISM DISORDERS}

Increasing or decreasing levels of lipids cause various health effects in the human body, which are called disorders. These types of disorders usually increase triglyceride, LDL, or both lipid levels. The body requires the useful fatty acid $\mathrm{HDL}$, which helps to transport bad cholesterol out of the body. Similarly, the accumulation of bad and unwanted lipids, such as fatty LDLs and triglyceride, damage the arteries and have serious consequences for cardiovascular health. Recently, Xiao et al. (2021) published an article on inherited complex lipid metabolism disorders, stating that over 80 diseases have been identified as complex lipid metabolism defects. They reviewed the physiological role of lipid metabolism in health disorders, which defines various metabolisms, such as nonlysosomal sphingolipids, acylceramides, etc. Lipid metabolismbased disorders were classified into five types by Fredrickson's, based on the pathway and health effects (Quispe et al., 2019). When compared to a lower level of lipids, a higher amount of lipid accumulation in the body causes more health disorders, which is known as hyperlipidemia (Natesan and Kim, 2021). Hyperlipidemia refers to a group of serious lipid disorders caused by an abnormally high level of unwanted lipids in the blood (Verma, 2017). The Verma's review classified hyperlipidemia based on the lipid type (Fig. 1) (Verma, 2017). Verma (2017) reviewed Fredrickson's familial disorders classifications, symptoms, and treatments for each kind of disorder (Fredrickson and Lee, 1965).

The discrete lipid metabolic disorders classification varies based on concentrations of classes of lipoproteins, and several disorders are now observable with structural defects in the presence or absence of apolipoproteins and lipid transfer proteins, respectively (Schonfeld, 1990).

The peroxisome proliferator-activated receptors are a type of lipid, which are also called nuclear fatty acid receptors, that have been associated with playing a vital role in obesity connected to metabolic diseases like coronary artery disease,

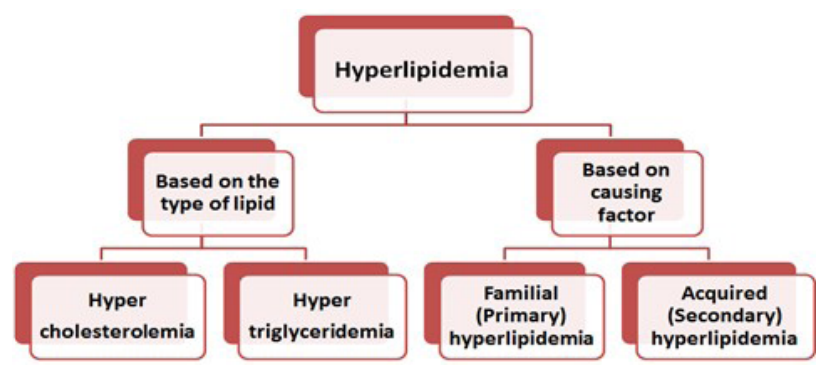

Fig. 1. Classifications of lipid metabolism disorders based on the nature of lipid and factors. hyperlipidemia, and insulin resistance (Azhar, 2010). The peroxisome proliferator-activated receptors involving regulated pathways that control various lipid disorders were also reported for medical treatment purposes (Lee et al., 2003). In addition, various lipid metabolism disorders, such as bone related disorders, osteoporosis, and atherosclerosis, are major worldwide health problems for postmenopausal females (Bagger et al., 2006). The hypothetical evidence proposes a relationship between lipid metabolism and bone, which are mutually regulated (Tian and Yu, 2015); however, some conflicting results were observed, which require some Chinese human subjects. Myopathy and the severity of carnitine deficiency are caused by the excessive accumulation of lipid droplets on muscle fibers (Di Mauro et al., 1980). Metabolic systems of lipids or lipid abnormalities cause various disorders and diseases. Furthermore, excess lipid storage in the body causes a variety of disorders, including xanthoma, Bassen-Kornzweig syndrome, methylmalonic acid blood test, chylomicronemia syndrome, familial lipoprotein lipase deficiency, Niemann-Pick disease (NPD type-A and NPD type-B), methylmalonic academia, GM1 \& GM2 gangliosidoses, Gaucher disease, Aside from these, the more serious consequences are cardiovascular disorders and diabetes, both of which had no symptoms at the time. Nowadays, these are the major health issues in the digital world. The most common causes of acquired hyperlipidemia are diabetes mellitus, alcohol consumption, hypothyroidism, renal failure, nephrotic syndrome, and continuous use of diuretics, estrogens, and $\beta$-blockers (Stone, 1994; Reckless and Lawrence, 2003).

\section{CLASSIFICATION OF LIPID METABOLISM DISORDERS}

The best way of classifying lipid metabolism disorders is descriptively (Table 1), based on the changes in concentration of the various types of lipids. LDL hypercholesterolemia is distinguished from mixed hyperlipoproteinemia, hypertriglyceridemia, and an isolated reduction in HDL cholesterol. All of these lipid metabolism disorders can be associated with elevated lipoprotein(a). The treatment of the individual lipid metabolism disorders is described below.

\section{EXCLUSION OF SECONDARY LIPID METABOLISM DISORDERS}

Secondary lipid metabolism abnormalities can cause a variety of illnesses. Diabetes mellitus, hypothyroidism (LDL hypercholesterolemia), renal illnesses (hypertriglyceridemia, mixed hyperlipoproteinemia, lipoprotein elevation), and cholestatic liver disorders are the most common clinically. Lipid

Table 1. Descriptive classification of the dyslipoproteinemias

\begin{tabular}{lcccc} 
& LDL hypercholesterolemia & Hypertriglyceridemia & Mixed hyperlipoproteinemia & Low HDL \\
\hline Cholesterol & Increased & Increased & Increased & Unchanged \\
Triglycerides & Unchanged & Increased & Increased & Unchanged \\
LDL cholesterol & Increased & Unchanged & Increased & Unchanged \\
HDL cholesterol & Unchanged & Decreased & Decreased & Decreased \\
\hline
\end{tabular}


metabolism disorders have also been found in the setting of other illnesses (e.g., lymphoma, Cushing syndrome, and porphyria). When the lipid metabolism problem is a secondary manifestation, the primary emphasis of treatment should be on the underlying illness. People with chronic diabetes or renal illness are frequently outliers to this rule, because adequate control or eradication of the underlying disease is not accomplished, and they exhibit symptoms of both primary and secondary lipid metabolism problems.

\section{LIFESTYLE MODIFICATION}

Lifestyle changes are important in the treatment of lipid metabolism problems. Regardless of the treatments used, the decrease in high LDL cholesterol concentrations seldom exceeds $10 \%$ (Malhotra et al., 2014). The biggest impact is obtained by reducing the consumption of saturated fatty acids, namely animal fats. Because the influence of orally ingested cholesterol is small, the current recommendations in the United States do not advise limiting cholesterol consumption at all. Lifestyle modifications, alone or in conjunction with changes in lipid concentrations, have a significantly larger effect on hypertriglyceridemia. Severe limits on alcohol consumption and a reduction in the intake of quickly absorbed carbohydrates can reduce triglyceride levels by more than $50 \%$ (Hegele et al., 2014). Regular exercise also increases the lipid profile. Even if the effect on lipid concentration is modest in certain situations, lifestyle changes might have a positive influence on the risk profile. In high-risk individuals, for example, a Mediterranean diet supplemented with extra olive oil or almonds results in a 30\% reduction in relative risk (Estruch et al., 2013). Surprisingly, consuming nuts lowers LDL cholesterol; thus, it is debatable that at least some of the risk reduction is due to a beneficial impact on the lipid profile (Wu et al., 2014).

\section{LDL HYPERCHOLESTEROLEMIA}

According to European recommendations, the target concentration of LDL cholesterol should be determined by the total risk. If lifestyle changes alone are insufficient to achieve this aim, statin medication is the initial step in medical therapy. If the goal LDL cholesterol level is not reached after 4 to 6 weeks of therapy, the dose should be modified. In high-risk individuals, both lifestyle changes and statin therapy should begin at the same time (Catapano et al., 2011). According to the results of the IMPROVE-IT trial, ezetimibe should be administered if statin therapy alone fails to attain the target LDL cholesterol concentration. If the combination of a statin and ezetimibe is still ineffective, PCSK9 antibodies might be used. Patients with atherosclerosis and resistant LDL hypercholesterolemia might be treated with frequent lipid apheresis as a last option.

In Germany, other statins (lovastatin, fluvastatin, pravastatin, rosuvastatin, pitavastatin) play a limited role. Fluvastatin and pravastatin have lower side effect rates than atorvastatin and simvastatin; thus, they can be used in individuals who cannot take the latter (Stroes et al., 2015). Rosuvastatin has a very potent LDL cholesterol-lowering effect; however, patients in Germany must bear a portion of the expenditure. Acute coronary syndrome (ACS) is a unique condition. Ini- tial research indicates that extremely early high-dose statin treatment improves the prognosis of ACS patients (Cannon et al., 2004). The most probable reason is that LDL cholesterol has no effect on endothelial function (Sparrow et al., 2001). In the meantime, however, these findings are being viewed with caution. Nonetheless, most recommendations suggest that patients with ACS begin therapy with a high-dose statin.

\section{MIXED HYPERLIPOPROTEINEMIA}

Because of its strong connection with metabolic syndrome, mixed hyperlipoproteinemia, characterized by elevated levels of both LDL cholesterol and triglycerides, is the most common lipid metabolism disease in diabetics (Wu and Parhofer, 2014). In this case, too, the primary therapeutic objective is to keep LDL cholesterol levels in check. The essential measure in the treatment of hypertriglyceridemia is a change in the patient's lifestyle. If the combination of lifestyle changes and statin medication does not achieve the desired concentrations, or at least normalize the triglyceride level, combined medical treatment may be explored (Hegele et al., 2014). In theory, statins can be used with omega-3 fatty acids or fibrates, although both of these combinations have performed poorly in endpoint trials (Kromhout et al., 2010). However, due to the poor design of these trials, no conclusive result can be drawn, as each of these two classes of drugs decreased cardiovascular risk in monotherapy studies (Chaudhury et al., 2017). In our facility, patients with very high risk and a combined lipid metabolic problem are treated with statin + fibrate or statin + omega-3 fatty acids after all other LDL cholesterol-lowering options have been exhausted. Without comparative research, neither of these two therapies can be favored over the other. It may be advisable to test both combinations and then stick with the one that is best tolerated and produces the greatest results.

\section{HYPERTRIGLYCERIDEMIA}

Triglyceride levels are frequently much higher than normal in isolated hypertriglyceridemia, whereas LDL cholesterol levels are modest. Total cholesterol levels might be high. Isolated hypertriglyceridemia, like mixed hyperlipoproteinemia, typically responds favorably to lifestyle changes. Moreover, there is no way to predict whether a specific patient will react well or poorly. Because no compelling studies have been published, there is no agreement on when medical therapy should begin (Yuan et al., 2007). However, the threshold is lower among people at high risk of atherosclerosis than when hypertriglyceridemia is detected accidentally in an otherwise healthy person. A fibrate can be administered if the triglyceride level remains above $400 \mathrm{mg} / \mathrm{dL}(4.6 \mathrm{mmol} / \mathrm{L})$, after the application of lifestyle modification strategies. Fenofibrate and gemfibrozil appear to be the best alternatives. Alternatively, omega- 3 fatty acids can be administered alone or in combination, as necessary (Hegele et al., 2014). Statins are typically ineffective in isolated hypertriglyceridemia since LDL cholesterol is frequently already extremely low at the start. Patients with known atherosclerosis should get a modest dosage of statin regardless of LDL cholesterol levels.

There is general agreement that if the triglyceride level stays above $400 \mathrm{mg} / \mathrm{dL}$ ( $4.6 \mathrm{mmol} / \mathrm{L})$ despite implementation 
of lifestyle modification measures, a fibrate can be given. The best options seem to be fenofibrate or gemfibrozil (positive endpoint studies; should not be combined with statins). Alternatively, omega-3 fatty acids can be given, in combination if indicated (Hegele et al., 2014). Statins are generally of little use in isolated hypertriglyceridemia, because the LDL cholesterol is often already very low at the outset. Clients with known atherosclerosis should be given a modest dose of statins, regardless of LDL cholesterol levels.

\section{SYMPTOMS OF HYPERLIPIDEMIA}

In general, hyperlipidemia disorders do not have any noticeable symptoms, but they are regularly exposed by the health monitoring process or by routine examination and will cause a stroke or a heart attack if it reaches a dangerous stage. Patients with more than the maximum cholesterol level in the blood will be affected by xanthomas. In this disorder, cholesterol deposits itself under the skin and in the eyes (Shattat, 2014). A raised level of triglycerides was reported at the same time, causing numerous pimples in diverse sites of the patients' bodies. Familial hypercholesterolemia is a common autosomal-related disorder caused by elevated LDL cholesterol levels at birth. It also causes premature coronary artery disease and requires initial diagnosis to avoid expensive generic pharmacotherapy (McGowan et al., 2019).

\section{CARDIOVASCULAR DISORDER OR DISEASE (CVD)}

According to healthcare providers, the well-established stage of lipids in the body causes risk factors for CVD, and the analysis of lipid-screening test results plays a critical role in CVD risk assessment. The Framingham Risk Score is the most widely used authenticated lipid-screening technique (Nelson, 2013). CVD, or coronary heart disease, causes serious health issues, such as heart attack, heart failure, and stroke (Joynt et al., 2003). CVD is caused by chronic inflammatory atherosclerosis, which develops gradually in the human body over several years. The CVD risk factor dyslipidemia is related to lipid metabolism and is affected by genes and proteins. Computed tomography investigations on various lipid molecules, such as cholesteryl ester transfer protein, lipoprotein lipase, polymorphisms of paraoxonase 1 and 2, and hepatic lipase, were used to measure the relationship between CVD and lipid metabolism. The Diabetes Heart Study included 620 European American volunteers, with $83 \%$ having type 2 diabetes mellitus. The results revealed that the Q192R variant of paraoxonase 1 and rs285 of lipoprotein lipase were linked with carotid artery calcium $(p=0.002$ and 0.005 , respectively) and paraoxonase-2 S311C was connected with coronary artery calcium $(p=0.037)$, which was proven by Burdon et al. (2005). Goldberg et al. (2012) reported the lipid metabolism effect on the heart, observing that excess lipid accumulation causes severe chest pain by obstructing blood flow, reducing oxygen flow and resulting in a heart attack.

CVD kills one out of every three women. Sex-specific data concentrated on cardiovascular disease has been growing steadily. The average lifetime is reduced due to CVD in women who are at an age of approximately 50 years ( $\approx 40 \%)$. However, significant causes of CVD are depicted in Fig. 2 (Garcia et al., 2016).

\section{DIABETES MELLITUS}

Diabetes mellitus is another disorder caused by lipid metabolism that necessitates a continuous health monitoring strategy for long-term survival (Amalan and Vijayakumar, 2015). The impact of insulin on lipid metabolism, which is influenced by diabetes, may be measured in four different ways (Saudek and Eder, 1979). The proposed mechanism exposed the negative and positive effect on insulin in the regulation of triglyceride metabolism.

Lipid metabolism is altered and changes are observed during Gestational Diabetes Mellitus and the normal pregnancy period. Hepatic and adipose metabolism alters the concentrations of triacylglycerols, cholesterol, phospholipids, and fatty acids (Amalan et al., 2015). Then, in the first 8 weeks of pregnancy, there is a preliminary decrease, followed by a gradual increase in the majority of the fatty acid or lipid concentrations. At the same time, the higher concentrations of estrogen and insulin resistance are believed to be accountable for the hypertriglyceridemia of pregnancy (Butte, 2000). Their research on pregnant women with GDM has revealed that diet control and exercise have managed their diabetes.

Diabetic dyslipidemia is a collection of many irregularities in fat, both LDL and HDL intolerance levels. This pattern of lipoprotein deviations is extremely atherogenic and is associated with a rise in plasma triglyceride levels. The clinical irregularities take place at a range of plasma triglyceride levels, which represent the upper normal range or mild hypertriglyceridemia $(>1.5 \mathrm{mmol} / \mathrm{L})$. In clinical practice, this means that triglyceride levels should be maintained as low as possible in non-insulin dependent diabetes mellitus patients (Taskinen et al., 1996).

An experimental report on the regulation of lipids with glucose metabolism in the post absorptive and postprandial conditions in six subjects (selective patients or volunteers)

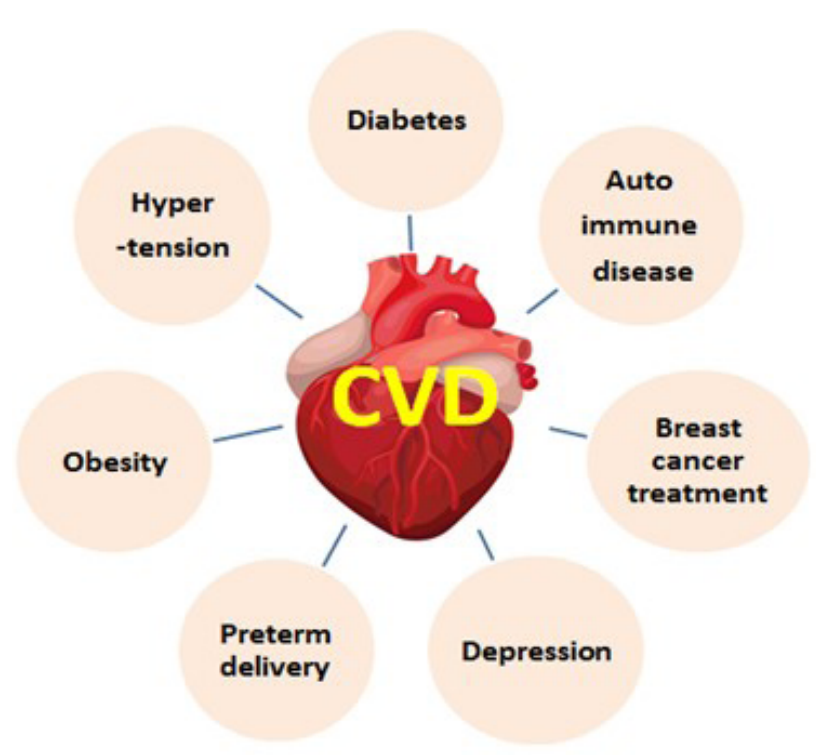

Fig. 2. Various reasons for cardiovascular disorders by lipids storage related metabolic actions. 


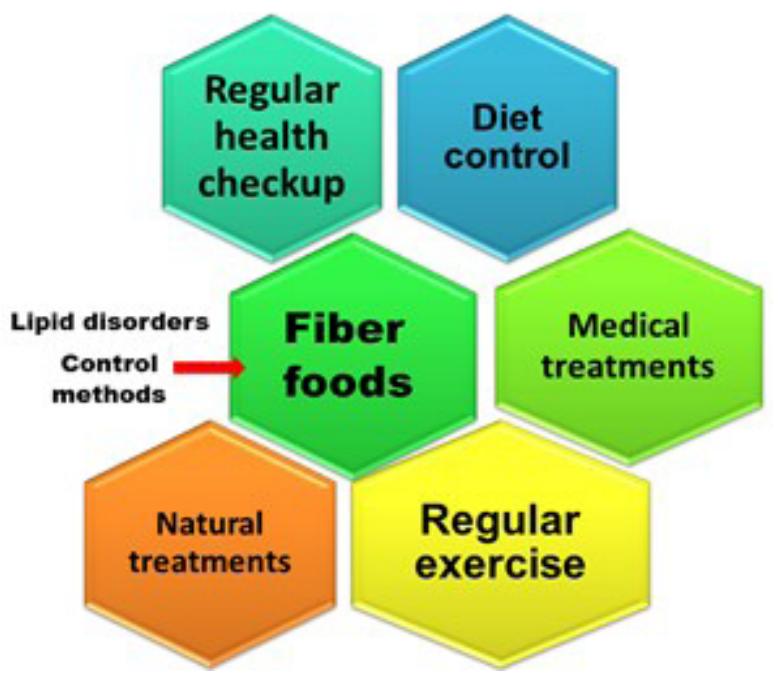

Fig. 3. Methods of controlling lipid disorder. with insulin-treated diabetes mellitus, matched with eight nondiabetic volunteers or subjects, involved the investigation of blood or plasma concentrations of metabolites and fluxes across forearm and subcutaneous adipose tissue after an overnight fast and for 6 hours after a mixed meal (3.1 MJ, $41 \%$ from fat). The observation revealed that the wider spread of plasma (free) insulin concentrations in the diabetic group led to a wider range of plasma non-esterified fatty acid release from adipose tissue, plasma NEFA concentrations, and blood ketone body concentrations (Frayn et al., 1993). These studies and reviews have confirmed lipid metabolism and its impact on health issues in different ways.

\section{CONTROL AND TREATMENT METHODS}

These kinds of lipid-based disorders can be controlled by various methods, such as physical methods, a controlled food system, therapeutic lifestyle changes, drug therapy, and proper health checkups (Fig. 3). Statins are the most potent class of medicine used for cardiovascular diseases. Being cholesterol-lowering drugs, statins are expected to ameliorate the cardiovascular problem, which lowers the acute-phase

Table 2. Anti-lipidemia drugs and their mechanism with side effects

\begin{tabular}{|c|c|c|}
\hline Drug & Mechanism & Adverse effects \\
\hline $\begin{array}{l}\text { Statins } \\
\text { Simvastatin, Atorvastatin } \\
\text { Rosuvastatin }\end{array}$ & $\begin{array}{l}\text { Limiting the cholesterol formation in the liver, } \\
\text { inhibition HMG CoA reductase }\end{array}$ & $\begin{array}{l}\text { Gastrointestinal upset, Liver function tests may } \\
\text { become deranged, Myalgia, myositis, muscle } \\
\text { symptoms }\end{array}$ \\
\hline $\begin{array}{l}\text { Bile acid-binding (anion } \\
\text { exchange) resins }\end{array}$ & All cholesterol from bile acids are reabsorbed & $\begin{array}{l}\text { Unpalatable taste, texture of the medication, con- } \\
\text { stipation }\end{array}$ \\
\hline Nicotinic acid and derivatives & $\begin{array}{l}\text { Reduce lipolysis and the availability of free fatty } \\
\text { acids. }\end{array}$ & $\begin{array}{l}\text { Gastrointestinal disturbance,Vomiting, dyspepsia, } \\
\text { headache and dizziness }\end{array}$ \\
\hline Omega-3 fatty acid & Competitively block triglyceride synthesis & $\begin{array}{l}\text { Gastrointestinal disturbance, prolonged bleeding } \\
\text { time }\end{array}$ \\
\hline Mevastatin & Lowers LDL-C concentration & Depression, anxiety, indigestion \\
\hline Lovastatin & Same as above & Headache, rashes, gastrointestinal symptoms \\
\hline Pravastatin & Same as above & Depression, anxiety, alopecia \\
\hline Clofibrate & Lowers serum TG. concentration & Nausea, diarrhoea, arthralgias \\
\hline Gemfibrozil & Lowers plasma TG by $40-55 \%$ & Abdominal pain, nausea, diarrhoea \\
\hline Fenofibrate & $\begin{array}{l}\text { Lowers plasma LDL-C concentration and rise } \\
\text { HDL-C concentration }\end{array}$ & Nausea, constipation, skin rashes \\
\hline Ciprofibrate & Same as above & Constipation, skin rashes \\
\hline Benzafibrate & Supresses endogenous chol and TG synthesis & Myalgia, diarrhoea, skin rashes \\
\hline Simfibrate & Lowers Chol and TG concentration & Skin rashes, nausea, myalgia \\
\hline Etofibrate & Lowers VLDL and LDL concentration & Flushing \\
\hline Probucol & Lowers plasma Chol by $10-15 \%$ & Flatulence, eosinophilia, paresthesia \\
\hline Neomycin & Same as above & Malabsorption diarrhoea \\
\hline$\beta$-Sitosterol & Same as above & Laxative effect, vomiting \\
\hline Dextro Thyroxin & Lowers plasma LDL-C concentration & Serious cardiac toxicity \\
\hline Aminosalicylic acid & Same as above & Steatorrhea \\
\hline Tiadenol & Lowers plasma Chol level & Nausea \\
\hline Sorbinicate & Lowers Chol and TG plasma level & Malabsorption \\
\hline Cholestyramin & Binds bile acid resulting Chol catabolism & Nausea, indigestion \\
\hline Colestipol & Lowers plasma LDL-C levels & Nausea, constipation \\
\hline
\end{tabular}

This shows a list of anti-lipidemia drugs and their mechanism in fat or cholesterol control at different parts of body using different metabolic chemicals along with drugs side effects. 
proteins (Pahan, 2006). Table 2 shows some anti-lipidemia drugs, as well as their mechanisms and side effects (Waller and Waller, 2014; Dias et al., 2018).

\section{CONTROL OF SATURATED VS. UNSATURATED FATTY ACIDS (FAS)}

The amounts of saturated FAs incorporated in cell membrane phospholipids change, depending on the source of FAs, de novo lipogenesis, or external lipid absorption. The lipogenic process raises the saturation level of cell membranes with saturated and monounsaturated fatty acids (MUFAs) (Yue et al., 2014; Fernandez et al., 2020), which are less susceptible to lipid peroxidation than the polyunsaturated acyl chains (PUFAs) acquired mostly via food. In this approach, de novo lipogenesis helps to make cancer cells resilient to oxidative stress and chemotherapy (Rysman et al., 2010).

Nonetheless, an excess of saturated FAs in cell membranes might cause lipotoxicity. In this context, SCD1 inhibition promotes endoplasmic reticulum (ER) stress and death in cancer cells and reduces tumor development in colon and lung cancer xenograft models. The core regions of tumors are subjected to hypoxia and decreased nutritional availability during tumor development. Tumors have evolved several techniques for balancing the amounts of saturated vs. unsaturated FAs and anticipate lipotoxicity by increasing MUFA/PUFA absorption from plasma, which is then stored in lipid droplets (LDs) or integrated into phospholipids at the cell membranes. Because SCD1 activity requires oxygen, certain cancers rely on the activity of diglyceride acyltransferase (DGAT) during hypoxia to integrate MUFAs into triglyceride (TG), which is then deposited into LDs (Fernandez et al., 2020). Furthermore, cancers regulate the amounts of saturated vs. unsaturated FAs in phospholipids at the cell membranes via the Lands cycle. Recently, a mechanism known as ferroptosis has been identified, which is related with high amounts of MUFA/PUFAs in cell membrane phospholipids, causing cell death by oxidation via the Fenton pathway. Long-chain FA acyl CoA synthetases (ACSLs), which are involved in long chain FA activation, may regulate ferroptosis, because different isoforms employ different substrates. Conversely, although ACSL4's major substrates are PUFAS, such as AA, ACSL3 may activate both MUFAs and PUFAs, allowing for better regulation of PUFA buildup in phospholipids (Alwarawrah et al., 2016). Furthermore, ACSL3 provides for better regulation of FA distribution between LD storage and fatty acid oxidation (FAO), allowing for better management of oxidative stress.

\section{CURRENT TREATMENT MODALITIES}

A variety of novel methods for the treatment of lipid metabolism diseases have been explored. Proprotein convertase subtilisin/kexin type 9 (PCSK9) antibodies are particularly significant (Stein et al., 2013). Even in individuals who have previously had combination statin and ezetimibe treatment, these medicines can result in a 50 to $60 \%$ decrease in LDL cholesterol (Blom et al., 2014). PCSK9 antibodies have just a little effect on triglyceride and HDL cholesterol concentrations. They do, however, reduce lipoprotein(a) levels by up to $30 \%$ (Raal et al., 2014; Parhofer, 2016). Until the endpoint comprehen- sive research is completed and published, PCSK9 antibodies can only be given to carefully selected patients, such as those with known atherosclerosis and prominent LDL hypercholesterolemia who cannot be treated by other means due to their levels being too high or who are unaware of statins.

\section{CONCLUSION}

Hyperlipidemia, a major cause of coronary heart disease, diabetes, and cancer, is prevalent throughout the world. Numerous studies and reviews have been reported on metabolism, the causes of lipid-based disorders, and the effects of fatty acids. Despite the fact that many drugs are available on the market, society continues to face problems as a result of CVD. To minimize the risk of cardiovascular related heart failure, heart attacks due to hyperlipidemia need novel drugs that can decrease lipids such as cholesterol and triglycerides in the blood. This review mainly focuses on compiling reports on lipids, metabolism, CVD, and diabetes related issues. Still, there is no complete report on lipid metabolism disorders and drug discovery. As a result, this review has been launched with only the most basic reports for further investigation.

\section{REFERENCES}

Ahmed, S., Shah, P. and Ahmed, O. (2021) Biochemistry, lipids. In: StatPearls, pp. 11-19. StatPearls Publishing, Treasure Island.

Alves-Bezerra, M. and Cohen, D. E. (2017) Triglyceride metabolism in the liver. Compr. Physiol. 8, 1-8.

Alwarawrah, Y., Hughes, P., Loiselle, D., Carlson, D. A., Darr, D. B., Jordan, J. L., Xiong, J., Hunter, L. M., Dubois, L. G., Thompson, J. W., Kulkarni, M. M., Ratcliff, A. N., Kwiek, J. J. and Haystead, T. A. (2016) Fasnall, a selective FASN inhibitor, shows potent anti-tumor activity in the MMTV-Neu model of HER2(+) breast cancer. Cell Chem. Biol. 23, 678-688.

Amalan, V. and Vijayakumar, N. (2015) Antihyperglycemic effect of p-coumaric acid on streptozotocin induced diabetic rats. Indian J. Appl. Res. 5, 10-13.

Amalan, V., Vijayakumar, N. and Ramakrishnan, A. (2015) P-Coumaric acid regulates blood glucose and antioxidant levels in streptozotocin induced diabetic rats. J. Chem. Pharm. Res. 7, 831-839.

Arslan, N. (2014) Obesity, fatty liver disease and intestinal microbiota. World J. Gastroenterol. 44, 16452-16463.

Arumugam, R. and Natesan, V. (2017) Urea cycle pathway targeted therapeutic action of naringin against ammonium chloride induced hyperammonemic rats. Biomed. Pharmacother. 94, 1028-1037.

Athenstaedt, K. and Daum, G. (2006) The life cycle of neutral lipids: synthesis, storage and degradation. Cell. Mol. Life Sci. 63, 13551369.

Azhar, S. (2010) Peroxisome proliferator-activated receptors, metabolic syndrome and cardiovascular disease. Future Cardiol. 6, 657-691.

Bagger, Y. Z., Tankó, L. B., Alexandersen, P., Qin, G. and Christiansen, C.; Prospective epidemiological risk factors study group (2006) Radiographic measure of aorta calcification is a site-specific predictor of bone loss and fracture risk at the hip. J. Intern. Med. 259, 598-605.

Bazinet, R. P. and Layé, S. (2014) Polyunsaturated fatty acids and their metabolites in brain function and disease. Nat. Rev. Neurosci. 15, 771-785.

Blom, D. J., Hala, T., Bolognese, M., Lillestol, M. J., Toth, P. D., Burgess, L., Ceska, R., Roth, E., Koren, M. J., Ballantyne, C. M., Monsalvo, M. L., Tsirtsonis, K., Kim, J. B., Scott, R., Wasserman, S. M. and Stein, E. A.; DESCARTES Investigators (2014) A 52-week placebo-controlled trial of evolocumab in hyperlipidemia. N. Engl J. 
Med. 370, 1809-1819.

Burdon, K. P., Langefeld, C. D., Beck, S. R., Wagenknecht, L. E., Carr, J. J., Freedman, B. I., Herrington, D. and Bowden, D. W. (2005) Association of genes of lipid metabolism with measures of subclinical cardiovascular disease in the Diabetes Heart Study. J. Med. Genet. 42, 720-724.

Butte, N. F. (2000) Carbohydrate and lipid metabolism in pregnancy: normal compared with gestational diabetes mellitus. Am. J. Clin. Nutr. 71, 1256S-1261S.

Cani, P. D., Delzenne, N. M., Amar, J. and Burcelin, R. (2008) Role of gut microflora in the development of obesity and insulin resistance following high-fat diet feeding. Pathol. Biol. 56, 305-309.

Cannon, C. P., Braunwald, E., McCabe, C. H., Rader, D. J., Rouleau, J. L., Belder, R., Joyal, S. V., Hill, K. A., Pfeffer, M. A. and Skene, A. M.; Pravastatin or Atorvastatin Evaluation and Infection Therapy-Thrombolysis in Myocardial Infarction 22 Investigators (2004) Intensive versus moderate lipid lowering with statins after acute coronary syndromes. N. Engl. J. Med. 350, 1495-1504.

Castle, J. C., Hara, Y., Raymond, C. K., Garrett-Engele, P., Ohwaki, K., Kan, Z., Kusunoki, J. and Johnson, J. M. (2009) ACC2 is expressed at high levels in human white adipose and has an isoform with a novel N-terminus. PLOS ONE 4, e4369.

Catapano, A. L., Reiner, Z., De Backer, G., Graham, I., Taskinen, M. R., Wiklund, O., Agewall, S., Alegria, E., Chapman, M., Durrington, P., Erdine, S., Halcox, J., Hobbs, R., Kjekshus, J., Filardi, P. P., Riccardi, G., Storey, R. F. and Wood, D.; European Society of Cardiology (ESC); European Atherosclerosis Society (EAS) (2011) ESC/ EAS guidelines for the management of dyslipidaemias. The Task Force for the management of dyslipidaemias of the European Society of Cardiology (ESC) and the European Atherosclerosis Society (EAS). Atherosclerosis 217, 3-46.

Cena, H. and Calder, P. C. (2020) Defining a healthy diet: evidence for the role of contemporary dietary patterns in health and disease. Nutrients 12, 334.

Chaudhury, A., Duvoor, C., Reddy Dendi, V. S., Kraleti, S., Chada, A., Ravilla, R., Marco, A., Shekhawat, N. S., Montales, M. T., Kuriakose, K., Sasapu, A., Beebe, A., Patil, N., Musham, C. K., Lohani, G. P. and Mirza, W. (2017) Clinical review of antidiabetic drugs: implications for type 2 diabetes mellitus management. Front. Endocrinol. 8, 6 .

Church, C., Horowitz, M. and Rodeheffer, M. (2012) WAT is a functional adipocyte? Adipocyte 1, 38-45.

Coppens, I., Asai, T. and Tomavo, S. (2014) Chapter 8 - Biochemistry and metabolism of Toxoplasma gondii: carbohydrates, lipids and nucleotides. In Toxoplasma Gondii (2nd ed.) (L. M. Weiss and K. Kim, Eds.), pp. 257-295. Academic Press.

Denisenko, Y. K., Kytikova, O. Y., Novgorodtseva, T. P., Antonyuk, M. V., Gvozdenko, T. A. and Kantur, T. A. (2020) Lipid-induced mechanisms of metabolic syndrome. J. Obes. 2020, 5762395.

Di Mauro, S., Trevisan, C. and Hays, A. (1980) Disorders of lipid metabolism in muscle. Muscle Nerve 3, 369-388.

Dias, S., Paredes, S. and Ribeiro, L. (2018) Drugs involved in dyslipidemia and obesity treatment: focus on adipose tissue. Int. J. Endocrinol. 4, 2637418.

Dibaise, J. K., Zhang, H., Crowell, M. D., Krajmalnik-Brown, R., Decker, G. A. and Rittmann, B. E. (2008) Gut microbiota and its possible relationship with obesity. Mayo Clin. Proc. 4, 460-469.

Doğan, E. S. K., Doğan, B., Fentoğlu, O. and Kırzıoğlu, F. Y. (2019) The role of serum lipoxin A4 levels in the association between periodontal disease and metabolic syndrome. J. Periodontal Implant Sci. 49, 105-113.

Estruch, R., Ros, E., Salas-Salvadó, J., Covas, M. I., Corella, D., Arós, F., Gómez-Gracia, E., Ruiz-Gutiérrez, V., Fiol, M., Lapetra, J., Lamuela-Raventos, R. M., Serra-Majem, L., Pintó, X., Basora, J., Muñoz, M. A., Sorlí, J. V., Martínez, J. A., and Martínez-González, M. A. (2013) Primary prevention of cardiovascular disease with a mediterranean diet. N Engl J Med 368,1279-1290.

Fahy, E., Cotter, D., Sud, M. and Subramaniam, S. (2011) Lipid classification, structures and tools. Biochim. Biophy. Acta 1811, 637-647.

Fahy, E., Subramaniam, S., Brown, H. A., Glass, C. K., Merrill, A. H., Jr., Murphy, R. C., Russell, D. W., Seyama, Y., Shaw, W., Shimizu, T., Spener, F., van Meer, G., VanNieuwenhze, M. S., White, S. H.,
Witztum, J. L. and Dennis, E. A. (2005) A comprehensive classification system for lipids. J. Lipid Res. 46, 839-861.

Fernandez, L. P., Gómez, de Cedrón, M., Ramírez de Molina, A. (2020) Alterations of lipid metabolism in cancer: implications in prognosis and treatment. Front. Oncol. 10, 577420

Frayn, K. N., Coppack, S. W., Humphreys, S. M., Clark, M. L. and Evans, R. D. (1993) Periprandial regulation of lipid metabolism in insulin-treated diabetes mellitus. Metabolism 42, 504-510.

Fredrickson, D. S. and Lees, R. S. (1965) Editorial: a system for phenotyping hyperlipoproteinemia. Circulation 31, 321-327.

Garcia, M., Mulvagh, S. L., Bairey Merz, C. N., Buring, J. E. and Manson, J. E. (2016) Cardiovascular disease in women: clinical perspectives. Circ. Res. 118, 1273-1293.

Glass, C. K. and Olefsky, J. M. (2012) Inflammation and lipid signaling in the etiology of insulin resistance. Cell Metab. 15, 635-645.

Goldberg, I. J., Trent, C. M. and Schulze, P. C. (2012) Lipid metabolism and toxicity in the heart. Cell Metab. 15, 805-812.

Grundy, S. M. (2009) Advancing drug therapy of the metabolic syndrome. Nat. Rev. Drug Discov. 8, 341.

Hegele, R. A., Ginsberg, H. N., Chapman, M. J., Nordestgaard, B. G., Kuivenhoven, J. A., Averna, M., Borén, J., Bruckert, E., Catapano, A. L., Descamps, O. S., Hovingh, G. K., Humphries, S. E., Kovanen, P. T., Masana, L., Pajukanta, P., Parhofer, K. G., Raal, F. J., Ray, K. K., Santos, R. D., Stalenhoef, A. F., Stroes, E., Taskinen, M. R., Tybjærg-Hansen, A., Watts, G. F. and Wiklund, O.; European Atherosclerosis Society Consensus Panel (2014) The polygenic nature of hypertriglyceridaemia: implications for definition, diagnosis, and management. Lancet Diabetes Endocrinol. 2, 655-666.

Huang, C. and Freter, C. (2015) Lipid metabolism, apoptosis and cancer therapy. Int. J. Mol. Sci. 16, 924-949.

Huang, J., Borensztajn, J. and Reddy, J. K. (2011) Hepatic lipid metabolism. In: Molecular Pathology of Liver Diseases. Molecular Pathology Library, Vol. 5 (S. Monga, Ed.), pp. 133-146. Springer, Boston.

Hur, K. Y. and Lee, M. (2015) Gut microbiota and metabolic disorders. Diabetes Metab. J. 39, 198-203.

Joynt, K. E., Whellan, D. J. and Oconnor, C. M. (2003) Depression and cardiovascular disease: mechanisms of interaction. Biol. Psychiatry 54, 248-261.

Knopp, R. H. (1999) Drug treatment of lipid disorders. N. Engl. J. Med. 341, 498-511.

Kromhout, D., Giltay, E. J. and Geleijnse, J. M.; Alpha Omega Trial Group (2010) n-3 fatty acids and cardiovascular events after myocardial infarction. N. Engl. J. Med. 363, 2015-2026.

Lark, D. S., Fisher-Wellman, K. H. and Neufer, P. D. (2012) High-fat load: mechanism(s) of insulin resistance in skeletal muscle. Int. J. Obes. Suppl. 2, S31-S36.

Lattimer, J. M. and Haub, M. D. (2010) Effects of dietary fiber and its components on metabolic health. Nutrients 2, 1266-1289.

Lee, C. H., Olson, P. and Evans, R. M. (2003) Minireview: lipid metabolism, metabolic diseases, and peroxisome proliferator-activated receptors. Endocrinology 144, 2201-2207.

Leśniak, W., Bała, M. M., Płaczkiewicz-Jankowska, E., Topór-Mądry, R., Jankowski, M., Sieradzki, J. and Banasiak, W.; ARETAEUS2 Study Group (2015) Cardiovascular risk management in type 2 diabetes of more than 10-year duration: Results of Polish ARETAEUS2-Grupa Study. Cardiol. J. 22, 150-159.

Malhotra, A., Shafiq, N., Arora, A., Singh, M., Kumar, R. and Malhotra, S. (2014) Dietary interventions (plant sterols, stanols, omega-3 fatty acids, soy protein and dietary fibers) for familial hypercholesterolaemia. Cochrane Database Syst. Rev. 2014, CD001918.

McGowan, M. P., Hosseini Dehkordi, S. H., Moriarty, P. M. and Duell, P. B. (2019) Diagnosis and treatment of heterozygous familial hypercholesterolemia. J. Am. Heart Assoc. 8, e013225.

Monnerie, S., Comte, B., Ziegler, D., Morais, J. A., Pujos- Guillot, E. and Gaudreau, P. (2020) Metabolomic and lipidomic signatures of metabolic syndrome and its physiological components in adults: a systematic review. Sci. Rep. 10, 669.

Musso, G., Cassader, M., Paschetta, E. and Gambino, R. (2018) Bioactive lipid species and metabolic pathways in progression and resolution of nonalcoholic steatohepatitis. Gastroenterology 155 , 282-302.e8.

Nagy, K. and Tiuca, I.-D. (2017) Importance of fatty acids in phys- 
iopathology of human body. In Fatty Acids. IntechOpen. doi: 10.5772/67407.

Natesan, V. and Kim, S. J. (2021) Diabetic nephropathy - a review of risk factors, progression, mechanism, and dietary management. Biomol. Ther. (Seoul) 29, 365-372.

Nelson, R. H. (2013) Hyperlipidemia as a risk factor for cardiovascular disease. Prim. Care 40, 195-211.

Nilsson, P. M., Tuomilehto, J. and Rydén, L. (2019) The metabolic syndrome - what is it and how should it be managed? Eur. J. Prev. Cardiol. 26, 33-46.

Novgorodtseva, T. P., Karaman, Y. K., Zhukova, N. V., Lobanova, E. G., Antonyuk, M. V. and Kantur, T. A. (2011) Composition of fatty acids in plasma and erythrocytes and eicosanoids level in patients with metabolic syndrome. Lipids Health Dis. 10, 82

Ophardt, C. E. (2003) Overview of lipid function. In Virtual ChemBook. Elmhurst College. Available from: http://chemistry.elmhurst.edu/ vchembook/620fattyacid.html/.

Pahan, K. (2006) Lipid-lowering drugs. Cell. Mol. Life Sci. 63, 11651178.

Parhofer, K. G. (2016) The treatment of disorders of lipid metabolism. Dtsch. Arztebl. Int. 113, 261-268.

Pischon, T., Nöthlings, U. and Boeing, H. (2008) Obesity and cancer. Proc. Nutr. Soc. 67, 128-145.

Quispe, R., Hendrani, A., Baradaran-Noveiry, B., Martin, S., Brown E., Kulkarni, K., Banach, M., Toth, P. P., Brinton, E. A., Jones, S. R. and Joshi, P. (2019) Characterization of lipoprotein profiles in patients with hypertriglyceridemic Fredrickson-Levy and Lees dyslipidemia phenotypes: the Very Large Database of Lipids Studies 6 and 7. Arch. Med. Sci. 15, 1195-1202.

Raal, F. J., Giugliano, R. P., Sabatine, M. S., Koren, M. J., Langslet, G., Bays, H., Blom, D., Eriksson, M., Dent, R., Wasserman, S. M., Huang, F., Xue, A., Albizem, M., Scott, R. and Stein, E. A. (2014) Reduction in lipoprotein(a) with PCSK9 monoclonal antibody evolocumab (AMG 145): a pooled analysis of more than 1,300 patients in 4 phase II trials. J. Am. Coll. Cardiol. 63, 1278-1288.

Ratnayake, W. M. N. and Galli, C. (2009) Fat and fatty acid terminology, methods of analysis and fat digestion and metabolism: a background review paper. Ann. Nutr. Metab. 55, 8-43.

Reckless, J. P. D. and Lawrence, J. M. (2003) Hyperlipidemia (hyperlipidaemia). In Encyclopedia of Food Sciences and Nutrition (2nd ed.), pp. 3183-3192. Academic Press.

Rosca, M. G., Vazquez, E. J., Chen, Q., Kerner, J., Kern, T. S. and Hoppel, C. L. (2012) Oxidation of fatty acids is the source of increased mitochondrial reactive oxygen species production in kidney cortical tubules in early diabetes. Diabetes 61, 2074-2083.

Rysman, E., Brusselmans, K., Scheys, K., Timmermans, L., Derua, R., Munck, S., Van Veldhoven, P. P., Waltregny, D., Daniëls, V. W., Machiels, J., Vanderhoydonc, F., Smans, K., Waelkens, E., Verhoeven, G. and Swinnen, J. V. (2010) De novo lipogenesis protects cancer cells from free radicals and chemotherapeutics by promoting membrane lipid saturation. Cancer Res. 70, 8117-8126.

Saudek, C. D. and Eder, H. A. (1979) Lipid metabolism in diabetes mellitus. Am. J. Med. 66, 843-852.

Schonfeld, G. (1990) Inherited disorders of lipid transport. Endocrinol. Metab. Clin. North Am. 19, 229-257.

Shattat, G. F. A. (2014) Review article on hyperlipidemia: types, treatments and new drug targets. Biomed. Pharmacol. J. 7, 399-409.

Solomon, M. and Muro, S. (2017) Lysosomal enzyme replacement therapies: Historical development, clinical outcomes, and future perspectives. Adv. Drug Deliv. Rev. 118, 109-134.

Song, X., Zhong, L., Lyu, N., Liu, F., Li, B., Hao, Y., Xue, Y., Li, J., Feng, Y., Ma, Y., Hu, Y. and Zhu, B. (2019) Inulin can alleviate metabolism disorders in ob/ob mice by partially restoring leptin-related pathways mediated by gut microbiota. Genomics Proteomics Bioinfor- matics 17, 64-75.

Sparrow, C. P., Burton, C. A., Hernandez, M., Mundt, S., Hassing, H., Patel, S., Rosa, R., Hermanowski-Vosatka, A., Wang, P. R., Zhang, D., Peterson, L., Detmers, P. A., Chao, Y. S. and Wright, S. D. (2001) Simvastatin has anti-inflammatory and antiatherosclerotic activities independent of plasma cholesterol lowering. Arterioscler. Thromb. Vasc. Biol. 21, 115-121.

Stein, E. A., Honarpour, N., Wasserman, S. M., Xu, F., Scott, R. and Raal, F. J. (2013) Effect of the proprotein convertase subtilisin/ kexin 9 monoclonal antibody, AMG 145, in homozygous familial hypercholesterolemia. Circulation 128, 2113-2120.

Stone, N. J. (1994) Secondary causes of hyperlipidemia. Med. Clin. North Am. 78, 117-141.

Stroes, E. S., Thompson, P. D., Corsini, A., Vladutiu, G. D., Raal, F. J., Ray, K. K., Roden, M., Stein, E., Tokgözoğlu, L., Nordestgaard, B. G., Bruckert, E., De Backer, G., Krauss, R. M., Laufs, U., Santos, R. D., Hegele, R. A., Hovingh, G. K., Leiter, L. A., Mach, F., März, W., Newman, C. B., Wiklund, O., Jacobson, T. A., Catapano, A. L., Chapman, M. J. and Ginsberg, H. N.; European Atherosclerosis Society Consensus Panel (2015) Statin-associated muscle symptoms: impact on statin therapy-European Atherosclerosis Society Consensus Panel Statement on Assessment, Aetiology and Management. Eur. Heart J. 36, 1012-1022.

Taskinen, M. R., Lahdenperä, S. and Syvänne, M. (1996) New insights into lipid metabolism in non-insulin-dependent diabetes mellitus. Ann. Med. 28, 335-340.

Tian, L. and Yu, X. (2015) Lipid metabolism disorders and bone dysfunction-interrelated and mutually regulated (review). Mol. Med. Rep. 12, 783-794.

Tocher, D. R. (2003) Metabolism and functions of lipids and fatty acids in teleost fish. Rev. Fish. Sci. 11, 107-184.

Tracey, T. J., Steyn, F. J., Wolvetang, E. J. and Ngo, S. T. (2018) Neuronal lipid metabolism: multiple pathways driving functional outcomes in health and disease. Front. Mol. Neurosci. 11, 10.

Trebatická, J., Dukát, A., Ďuračková, Z. and Muchová, J. (2017) Cardiovascular diseases, depression disorders and potential effects of omega-3 fatty acids. Physiol. Res. 66, 363-382.

Uttaro, A. (2006) Biosynthesis of polyunsaturated fatty acids in lower eukaryotes. IUBMB Life 58, 563-571.

Verma, N. (2017) Introduction to hyperlipidemia and its treatment: a review. Int. J. Curr. Pharm. Res. 9, 6-14.

Waller, J. R. and Waller, D. G. (2014) Drugs for lipid disorders, antiplatelet drugs and fibrinolytics. Medicine 42, 544-548.

Wu, L. and Parhofer, K. G. (2014) Diabetic dyslipidemia. Metabolism 63, 1469-1479.

Wu, L., Piotrowski, K., Rau, T., Waldmann, E., Broedl, U. C., Demmelmair, H., Koletzko, B., Stark, R. G., Nagel, J. M., Mantzoros, C. S. and Parhofer, K. G. (2014) Walnut-enriched diet reduces fasting non-HDL-cholesterol and apolipoprotein B in healthy Caucasian subjects: a randomized controlled cross-over clinical trial. Metabolism 63, 382-391.

Xiao, C., Rossignol, F., Vaz, F. M. and Ferreira, C. R. (2021) Inherited disorders of complex lipid metabolism: a clinical review. J. Inherit. Metab. Dis. 44, 809-825.

Yan, J. and Horng, T. (2020) Lipid metabolism in regulation of macrophage functions. Trends Cell Biol. 30, 979-989.

Yuan, G., Al-Shali, K. Z. and Hegele, R. A. (2007) Hypertriglyceridemia: its etiology, effects and treatment. Can. Med. Assoc. J. 176, 1113-1120.

Yue, S., Li, J., Lee, S. Y., Lee, H. J., Shao, T., Song, B., Cheng, L., Masterson, T. A., Liu, X., Ratliff, T. L. and Cheng, J. X. (2014) Cholesteryl ester accumulation induced by PTEN loss and PI3K/AKT activation underlies human prostate cancer aggressiveness. Cell Metab. 19, 393-406. 